The data of patients with sFM were compared with the data of patients who did not report headache as a presentation symptom therefore not having FM with regards to age, disease duration, delay in diagnosis, disease activity (BASDAl) functional ability (BASFI), ESR, CRP and associated co morbidities from cardiovascular, respiratory, renal/urinary, and CNS systems. Central nervous system was evaluated by symptoms of dizziness and numbness.

Independent sample $\mathrm{T}$ test was used to explore differences between the 2 groups and confidence intervals obtained.

Results: Table shows demographics and disease characteristics as well as differences between SpA patients presenting with headache (indicating secondary FM), and those not presenting with headache. A greater proportion of patients with SpA and headache (sFM) report cardiovascular and CNS co-morbidities. There was no significant difference noted in the respiratory or renal/ urological co-morbidities amongst the 2 sub-groups.

Conclusions: A significantly higher proportion of patients described cardiovascular and CNS co-morbidities in the sFM group of SpA. No significant difference was noted in the 2 sub-groups with regards to the respiratory or renal systems.

Disclosure of Interest: None declared

DOI: 10.1136/annrheumdis-2017-eular.5474

\section{AB0716 PREVALENCE OF STRUCTURAL LESIONS TYPICAL FOR AXIAL SPONDYLOARTHRITIS IN YOUNG MILITARY RECRUITS BEFORE AND AFTER MECHANICAL STRESS}

G. Varkas ${ }^{1,2}$, M. de Hooge ${ }^{1}$, T. Renson ${ }^{1}$, P. Carron ${ }^{1,2}$, S. De Mits ${ }^{3}$, G. Souverijns ${ }^{4}$, D. Elewaut ${ }^{1,2}$, F. Van den Bosch ${ }^{1,2} .{ }^{1}$ Department of Rheumatology, Ghent University Hospital; ${ }^{2}$ VIB Inflammation Research Centre; ${ }^{3}$ Department of Rehabilitation Sciences and Physical Therapy, Ghent University, Gent; ${ }^{4}$ Department of Radiology, Jessa Ziekenhuis, Hasselt, Belgium

Background: Magnetic resonance imaging (MRI) has become the imaging modality of choice in early SpA. Not only has this imaging technique proven useful in the identification of inflammatory lesions on T2 FS/STIR sequences, also structural lesions such as erosions, sclerosis, fat infiltration and ankylosis can be seen on $\mathrm{T} 1$ sequences. There is still ongoing debate concerning the possible inclusion of any structural lesion in the definition of a positive MRI in order to improve specificity. However, erosions and fat infiltration have also been found in respectively more than $10 \%$ and $17 \%$ of non-SpA patients on MRI of the sacroiliac joints. [1]

Objectives: To evaluate the presence of structural lesions on MRI of the sacroiliac joints (MRI-SIJ) in young, asymptomatic subjects.

Methods: Twenty-five military recruits volunteered to perform a MRI-SIJ before and after 6 week of intense physical training, of which 22 recruits underwent imaging at both time points. The MRIs were scored for structural lesions by 3 trained readers $\mathrm{MdH}, \mathrm{GV}$ and TR, blinded for time sequence and clinical findings. Regarding the number of lesions a consensus was made by agreement of 2 out of 3 readers.

Results: At baseline, structural lesions were present in $36.4 \%$ (8/22) of subjects of which 5 subjects presented with at least 1 erosion, one subject with sclerosis and 3 subjects presented fatty lesions. This increased to $50 \%$ subjects $(11 / 22)$ with structural lesions on MRI-SIJ after 6 weeks of mechanical stress, of which 8 subjects with at least 1 erosion, one subject with sclerosis and 3 subjects with fatty lesions $(P=0.453)$. The change scores for sclerosis, erosions and fatty lesions were respectively $0.0( \pm 0.0), 0.2( \pm 0.1)$ and $0.3( \pm 0.2)$. None of the subjects displayed ankylosis. The lesion distribution is visualized in Table1.

Table 1. Number of structural lesions in young military recruits before and after intensive training

\begin{tabular}{lccc}
\hline $\mathrm{N}=22$ & Baseline & Week 6 & P-value \\
\hline Sclerosis & & & \\
$\quad$ Mean $( \pm \mathrm{SD})$ & $0.05( \pm 0.05)$ & $0.05( \pm 0.05)$ & 1.00 \\
$\quad$ Median $(25,75$ percentile) & $0.0(0.0,0.0)$ & $0.0(0.0,0.0)$ & \\
Erosions & & & \\
$\quad$ Mean $( \pm \mathrm{SD})$ & $0.32( \pm 0.14)$ & $0.55( \pm 0.17)$ & 0.096 \\
$\quad$ Median $(25,75$ percentile) & $0.0(0.0,0.25)$ & $0.0(0.0,1.0)$ & \\
Fatty lesions & $1.0( \pm 0.86)$ & $1.3( \pm 1.0)$ & 0.285 \\
$\quad$ Mean $( \pm \mathrm{SD})$ & $0.0(0.0,0.0)$ & $0.0(0.0,0.0)$ & \\
$\quad$ Median $(25,75$ percentile) & & & \\
\hline
\end{tabular}

Conclusions: Although not prevalent, structural lesions such as erosions, sclerosis and fatty lesions can be found in young asymptomatic subjects. However, these lesions do not seem to increase after 6 week of intense physical training.

\section{References:}

[1] Weber U, Lambert RG, Ostergaard M, Hodler J, Pedersen SJ, Maksymowych WP. The diagnostic utility of magnetic resonance imaging in spondylarthritis: an international multicenter evaluation of one hundred eighty-seven subjects. Arthritis Rheum. 2010;62(10):3048-58.

Acknowledgements: ASAS research grant 2017.

Disclosure of Interest: None declared

DOI: 10.1136/annrheumdis-2017-eular.5967

\section{AB0717 CONDUCTION DISTURBANCES IN A GROUP OF PATIENTS WITH AXIAL SPONDYLOARTHROPATHY}

${ }_{\text {H.S. Park }}{ }^{1}$, A. Laiz ${ }^{1}$, C. Alonso ${ }^{2}$, A. Garcia-Guillén ${ }^{1}$, M. Millán ${ }^{1}$, B. Magallares ${ }^{1}$, P. Moya ${ }^{1}$, I. Castellví ${ }^{1}$, C. Díaz-Torné ${ }^{1}$, J.M. De Llobet ${ }^{1} .{ }^{1}$ Rheumatology;

${ }^{2}$ Cardiology, Hospital de la Santa Creu i Sant Pau, Barcelona, Spain

Background: Cardiac conductance disturbances are known to be one of the many extra-articular manifestations of Ankylosing Spondilitis but not as well related to axial spondyloarthropathies.

Objectives: Description of conduction disturbances found in a group of patients with Axial Spondyloarthropathy (AxSpa) that met ASAS criteria.

Methods: Clinical and demographic variables of 78 patients with AxSpa were registered. It included cardiovascular risk factors as well as cardiacvascular adverse events. All of them had a routine electrocardiogram done which were analized by a cardiologist.

Results: 48 of the 78 patients were men, with a mean age of 61 with standard deviation (SD) of 14. The mean time of evolution of the disease was 23 years (SD \pm 16$)$. HLA-B27 was prevalent in $54(69.2 \%)$. The sacroileitis was found in radiologic examination of $72(92.2 \%)$, and $6(7.7 \%)$ of them presented edema in magnetic resonance imaging. Other clinical traits were: $43(55.1 \%)$ peripheric arthritis $43,8(10.3 \%)$ dactilitis, $33(42.3 \%)$ enthesitis, 16 uveitis (20.5\%), $2(2.6 \%)$ inflammatory bowel disease and psoriasis $34(43.3 \%)$. The following cardiovascular risk factors were registered: 25 (32\%) smokers, 42 (53\%) hypertension, $32(41 \%)$ dislipemia, $9(12 \%)$ diabetes, $9(12 \%)$ hyperuricemia and $20(20 \%)$ obesity. 14 patients had structural cardiopathy (11 ischemic cardiopathy and 3 aortic valvulopathy). The electrocardiographic register showed conductance disorders in 20 patients $(25.6 \%)$. The details of these findings are specified in table 1 .

\section{First grade auriculoventricular block}

Second and third grade auriculoventricular block

Left anterior fascicular block

Right bundle branch block

Unspecific intraventricular conduction disorder

Bachmann interatrial conduction disorder

Conclusions: A quarter of our series of presented conduction disturbances in electrocardiography. The relation with disease evolution, as in Ankylosing Spondilitis remains yet to be analized.

Disclosure of Interest: None declared

DOI: 10.1136/annrheumdis-2017-eular.4140

\section{AB0718 PREVALENCE OF RISK FACTORS FOR FRACTURES IN AXIAL SPONDYLOARTHRITIS: A SYSTEMATIC REVIEW}

J. Ramírez García ${ }^{1}$, R. Curbelo ${ }^{2}$, J.C. Nieto ${ }^{3}$, S. Castañeda ${ }^{4}$, L. Carmona ${ }^{2}$. ${ }^{1}$ Rheumatology, Hospital Clínic, Barcelona; ${ }^{2}$ Instituto de Salud

Músculoesquelética; ${ }^{3}$ Rheumatology, Hospital G.U. Gregorio Marañón;

${ }^{4}$ Rheumatology, Hospital de la Princesa, Madrid, Spain

Background: Spinal fractures occur more than expected in axial spondyloarthritis (Ax-Sp). However, it is not totally clear whether fracture risk depends solely on biomechanical problems of the spondyloarthritic spine or whether the prevalence of risk factors for fracture is larger than expected in these patients.

Objectives: To describe the prevalence of risk factors for osteoporotic fractures (both axial and peripheral) in Ax-Sp.

Methods: A systematic literature search was conducted. Medline, Embase and Cochrane Library databases were searched with a sensitive strategy including type of study and synonyms of Ax-Sp. All contemporary cross sectional studies or baseline results from representative cohorts of Ax-Sp published between January 2006 and 2016 were selected for detailed review. Only studies that fulfilled a minimum quality for survey data were included. Data on bone mineral density, prevalence of osteoporosis, and risk factor for fractures in Ax-Sp patients were collected.

Results: After screening 3597 titles and abstracts, only 43 studies (34 crosssectional, 3 prospective and 6 retrospective) were reviewed in detail. Of these, 20 studies compared Ax-Sp patients with a control group, either healthy individuals (17 studies) or subjects with other diseases (6 studies). Reported prevalence of osteoporosis varied from $2 \%$ to $39.6 \%$. Alcohol intake $(58-61 \%)$, use of corticosteroids (11.7-67\%), and $25-\mathrm{OH}$ vitamin D deficit (26-76\%) were unexpectedly high in Ax-Sp patients. All other factors were within expected frequencies for a not too old population.

Conclusions: Our systematic review found that alcohol intake, steroid use and 25-OH-vitamin D deficit should be taken into account when assessing comorbidity in Ax-Sp in order to avoid excess fractures.

Acknowledgements: this project was funded by Merck Sharp \& Dohme of Spain. Disclosure of Interest: None declared

DOI: 10.1136/annrheumdis-2017-eular.3539 